\title{
An Enhanced Algorithm of Safety Information Control using WSN in VANET
}

\author{
P.Karthikeyan, K.Sivaranjini, B.Gayathri, V.Priyadharshini
}

\begin{abstract}
Vehicular Ad hoc Networks (VANET) is the very most requesting technology territory in the area of (MANET) Mobile Ad Hoc Networks. Right now, propose a Beacon Power Control (BPC) convention that will be utilized for sending the periodic message. This calculation amplifies the successful inclusion of the communicate of security related data and in the interim fulfills the imperatives on both connection state and deferral. VANETs are considered as one of the significant structure in specially appointed system genuine application permitting interchanges among close by vehicles just as among vehicles and close by fixed hardware, normally depicted as a side of the road gear..
\end{abstract}

Keywords : deployment, throughput, routing, packet delivery ratio, routing overhead.

\section{INTRODUCTION}

$\mathrm{A}_{\text {vehicular impromptu system (VANET) give vehicle-to- }}$ vehicle and vehicle to the road side unit correspondence utilizing Dedicated Short Range Communications (DSRC). The center expectation of VANETs is to give wellbeing message correspondence among vehicles. Vehicular specially appointed system (VANET) is an assortment of vehicles furnished with remote correspondence capacity, indiscreetly shaping a system while proceeding onward the street. Vehicles collaborate to convey security related data through multi-bounce ways without the requirement for focal organization. The dissemination of wellbeing related data among vehicles out and about causes drivers to foresee unsafe occasions and development appropriately to stay away from potential hazardous occasions. With reasonable and make sure about remote correspondence between vehicles, VANET is engaged at giving traveler security by trading continuous traffic-peril messages among vehicles. Notwithstanding

Revised Manuscript Received on April, 022020.

* Correspondence Author

P.Karthikeyan*, computer science and engineering, sri manakula vinayagar engineering college, pudhucherry, india Email:mails2karthy@gmail.com.

K.Sivaranjini, computer science and engineering, sri manakula vinayagar engineering college, pudhucherry, india Email:sivaranjini482@gmail.com

B.Gayathri, computer science and engineering, sri manakula vinayagar engineering college, pudhucherry, india Email:gayu.gayathri1998@gmail.com

V.Priyadharshini, computer science and engineering, sri manakula vinayagar engineering college, pudhucherry, india Email:pdharshini705@gmail.com

(C) The Authors. Published by Blue Eyes Intelligence Engineering and Sciences Publication (BEIESP). This is an open access article under the CC BY-NC-ND license (http://creativecommons.org/licenses/by-nc-nd/4.0/) wellbeing related administrations, VANET can likewise offer show benefits by giving rapid Internet network locally available the vehicle. The unmistakable VANET topology and its dynamic remote sign condition represent a genuine test in VANET correspondence. Vehicle developments are bound by road maps, traffic signs and guidelines, and the development of encompassing vehicles. Subsequently, the circulation of vehicles is profoundly non-uniform, and the availability among them is exceptionally irregular. Besides, the unavoidable utilization of regular control channel for security applications makes correspondence profoundly powerless against impacts and impedance from both obvious and shrouded hubs. The one of a kind VANET qualities cause testing research worries in data proliferation and steering.

\section{RELATED WORK}

Intervehicular correspondence lies at the center of various industry and scholarly research frames that target overhauling the security and ability of transportation frameworks. Vehicular impromptu system (VANETs) permits the vehicles to speak with one another and also with road side units (RSU). Ad ministration situated vehicular systems are those which are special kinds of VANETs that includes particular structure based materialistic administrations, checking Internet get to, ongoing traffic the board, video gushing, and content spread. Numerous types of assaults contrary to support arranged VANETs that endeavor to undermine their security have raised. The achievement of information ownership and conveyance frameworks hold tight their capacity to shield against the various sorts of security and protection assaults that live in administration situated VANETs. This paper starts a framework that assumes responsibility for the RSUs that are appended to the Internet and that give a few sorts of data to VANET clients [1].Because of the monstrous capacity to guarantee street security and it improves driving experience, social Internet of Vehicle (SIOV) is turning into a valuable research point in both scholastic and mechanical circles. As the ever- expanding assortment, amount, and acumen of on-board machines, alongside the regularly developing interest for administration nature of autos, the best approach to give clients a scope of security-related and client arranged vehicular application has got significant. This paper focus on the structure of the help get to framework in SIOVs, which centers around a genuineness ensure plan and quality improvement technique. Initially, instead of the capriciousness of vehicular gadgets, a viable access administration examination conspire be investigated,

Published By:

Blue Eyes Intelligence Engineering

\& Sciences Publication

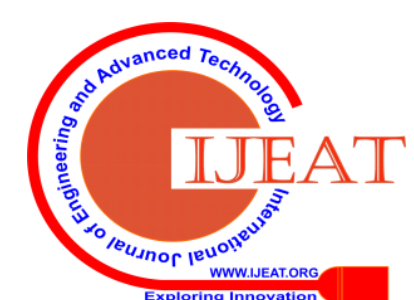




\section{An Enhanced Algorithm of Safety Information Control using WSN In VANET}

which assesses the potential pertinence of vehicles by building their social connections. Next, this work considers the direction based on relationship time projection calculation to make due with an insecure system topology and high pace of separation in SIOVs. Finally, a community oriented quality-mindful project framework is proposed here for administration access in SIOVs.Vehicular specially appointed systems (VANETs) are being wanted to update traffic security and capability. To meet this objective, the messages conveyed in VANETs must be dependable. We propose a detachment protecting framework that promising message mindful in vehicle-to- vehicle (V2V) interchanges. Vehicle sequestration is given up to a vehicle doesn't endeavor to support a similar message more than once. Regardless of a message having been legitimately embraced, on the off chance that it is later seen as bogus, the framework offers the chance of a posteriori following the message generator and its endorsers. Our proposition shows various obvious highlights. The framework is provided with both from the earlier and a posteriori help. The edge utilized for from the earlier affirmation can habituate change as indicated by the message criticalness and traffic setting, instead of being preset in the framework configuration arrange as in existing plans. The check of verified V2V messages is quickened by bunch message-preparing procedures [3]. A proficient certificateless open key cryptanalytics with balance model (CL-PKCET) to be proposed. The CL-PKC-ET plot is proposed right now, approved cloud server which permitted to delivers the uniformity model on encoded information, it afterward recovers the outcomes with no information on the important data about the figure content. Right now, point is to guarantee the information agglomerate through vehicle hubs which will be transferred to cloud through road side hubs, it is effectively agreeable from all over the place. The gathered information is encoded through the vehicle hubs earlier re-appropriating to the cloud.

Henceforth, just the approved client will get to the information from anyplace. For additional explanation, we imagine a situation that a police traffic office needs to know about all the vehicles which are all in specific location on given time. Every information that put away on the cloud server about these vehicles which is scrambled. Subsequently, the traffic police division should send an inquiry to cloud server which incorporates the particular period and area, that thus is look through the put away information and afterward result the data of vehicles that were available in the predetermined time and area. At last, the police traffic division can unscramble the query output got from the cloud server since the data to encoded utilizing the open key of the traffic police office. Encrypt likewise guarantees which the cloud specialist organizations included is not getting to clients' information without assent or unintentionally uncovering their information. Later on, the approved clients might need to get to this scrambled information and data and hence they need to look through it. This entire procedure would absolutely encounter significant expenses during calculation and dispersal. It would like a devour a great deal of time and when it isconsidered continuously application it will be ridiculous. Here the example scenario is show below, it is a graphical representation of the vanet showing the real world example of the traffic control it is very much useful for the police traffic control.

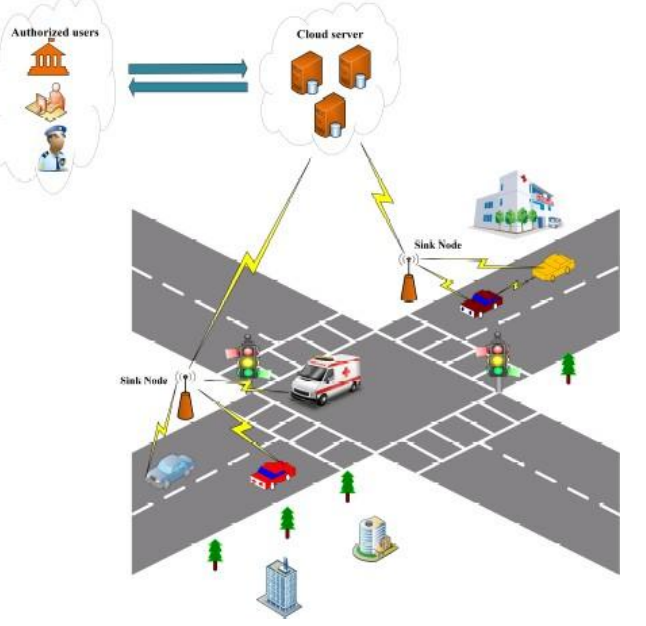

Fig. 1. A view of IOV

\section{A. Registration}

Right now, IOV hubs and the approved clients send the characters of the key age place . The KGC at that point restores the fractional private key to the IOV hubs and approved clients. At that point, the IOV hub and approved client can produce the full private key.

\section{B. Setup}

Right now, the scrambles that gathered information and re-appropriates that to the cloud server. Furthermore, the IOV hub creates that track that by utilizing the crypted key and passes on that to the cloud server. Likewise, thus approved client utilizes the client mystery lock to make the trap and it send by the system to cloud.

\section{Command}

Right now, an approved client wanted to send the information put away on to the cloud server, thus the client sends a question (watchwords) on to cloud server. The watchwords in inquiry rely upon what it approved client needed that. For instance, if it is approved client needs to recover scrambled information identified with a particular vehicle, thus question should have the vehicle number and different watchwords identified with the inquiry, for example, area, time, and so forth.

\section{Search}

Right now, cloud server is doled out to play out the equity test in the wake of getting the trapdoor of the IOV hubs and affirmed clients. The cloud servers at that point passes on the outcome to the approved clients. Note that, lone the approved client can play out the unscrambling of the outcome.The plan can be actualized to give a productive inquiry on the encoded information aggregated inside the cloud servers. This productive CL-PKC-ET plot take the element for its fairness test thus can play out the hunt within two watchwords scrambled under the diverse open key just as a similar open key. Moreover, the CL-PKC-ET plot is built under the certificateless privatesystem

Published By:

Blue Eyes Intelligence Engineering

\& Sciences Publication

(C) Copvriaht: All riahts reserved.

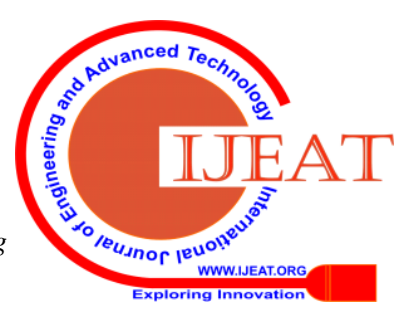

Retrieval Number: D7295049420/2020@BEIESP

DOI: 10.35940/ijeat.D7295.049420

Journal Website: www.ijeat.org 
\&\#40;CLC\&\#41;

Therefore, it is tackled the issues of endorsement the board which showed up with the correspondence test plans developed under the PKI cryptosystem.

\section{PROPOSED SYSTEM}

The Beacon Power Control(BPC) convention is prescribed to first detected and investigated the level about the Channel blockage, thus the outcome acquired remain utilized towards modify the transmission power as the wellbeing message to arrive at the ideal force. Every single vehicle communicates a status message considered reference point each $10 \mathrm{~ms}$, this guide consists of ID, arrangement, bearing, rate, time, stamp, guide interim, thus the hugeness from those signals was to provide the system status about the vehicles currently in progress and to ignore the traffic problems, also each and every vehicles must be provided with GPS gadget towards tracing the present position. Each guide acquired must be sorted out so as to receive data regarding the nearby vehicles and also about current system, the suggested reference point for discovering the proper force for transmission it has to hold data about the transmission capacity to assist the recipient.

The power data attached is piggybacked towards the present guide used in VANET. The data acquired from guides can be utilized so as to register current system clog, as signal shows up if the system isn't blocked and will neglect to arrive at its goal if there is something forestalling it. Vehicle additionally needs to consider over the specification among the two vehicles as the separation amplifies the level of got reference points will be decreased. The separation also be removed from the yielding of contemporary position gained from GPS and also the situation of the sender for making it simpler. Thus Every vehicle gathers its data involves Speed, Direction, position(GPS),Max power for transmission got and power utilized and includes them totally into the reference point.The vehicle can figure the distinction between the most extreme and least force got, the importance of the two got numbers and the base force got is a base force used to send and also these number can be utilized prosperously however it is also inadequate for the reference point for approaching each and every neighbor and the strongest force got for the guide thus this force makes the clog recently registered. uncertainly the most elevated force got must be diminished so as to decline the channel blockage and the base force must be expanded to guarantee that this guide will show up to additionally neighbors, yet this expansion must not surpass the greatest force got and the abatement and the expansion must not surpass the greatest force got and the abatement and the expansion must rely upon the clog acquired from the vehicle will arrive at the ideal force that it ought to transmit its reference points utilizing it.

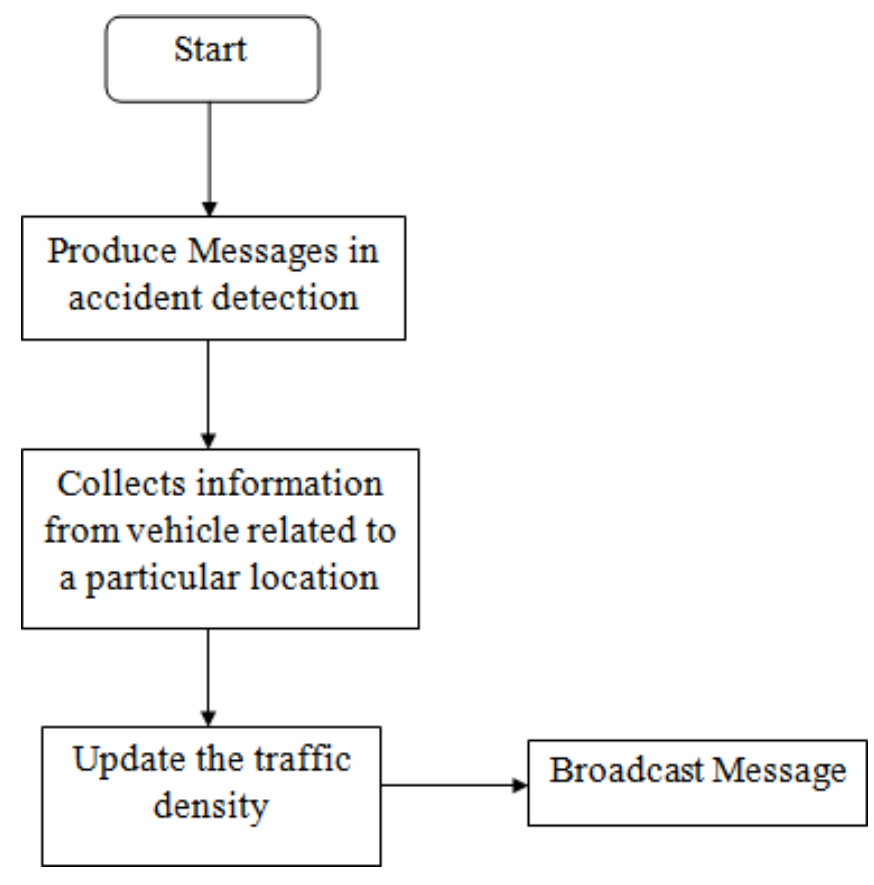

Fig. 2. Flow chart

Inspect the direct deterrent in each 1 second, thus each and every vehicle must receive 10 signals from each neighbor channel clog status at that point is used here to modify the transmission power. In the event that there is blockage, this induces most brought power spent in the channel will broaden this impede, so this force must be diminished so as to decrease the overhead acknowledged by most raised force utilized for correspondence in the channel, this ought to be possible. The upside of most decreased power used this is the least power could be used to ensure that the message will reach to its growth, lower power won't guarantee the reachability of these messages. This strong change for transmission power confirmations to reach to the perfect power that must be used. The redirect obstacle in every 1 second, as each vehicle must recognize 10 reference focuses from each neighbor; channel check status by then is utilized to adjust the transmission power, if there is hinder, this suggests most raised power used in the channel will construct this blockage, so this power must be reduced in order to diminish the overhead achieved by most prominent power used for transmission in the channel, the benefit of least power used this is the base power could be used in order to ensure that the message will reach to its improvement, lower power won't guarantee the reachability of these messages, this dynamic change for transmission power, confirmations to reach to the perfect power that must be used.

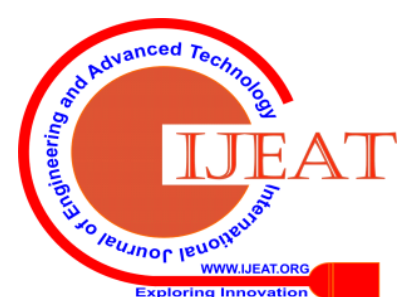




\section{A. Architecture of proposed system}

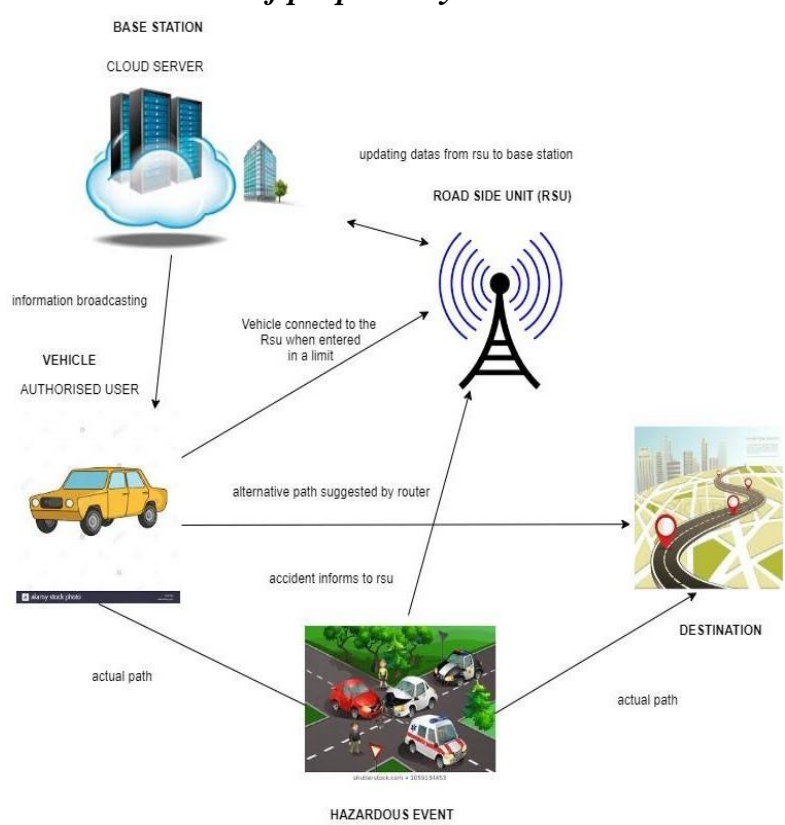

Fig. 3. Architecture Diagram

Fig.3. that shows the architecture of our proposed system. The vehicle goes into the restriction of a zone it gets associated with the street side unit(RSU).This RSU begins speak with the vehicle, The vehicle which is going along the genuine course it arriving at the goal. If any hazardous events happened in the route which is under the RSU limit send the message to the road side unit. The received information is further sensed and the information about the location and traffic will be collected through the wireless sensors. Once the message received is collected and it get send to the base station which is centralized for a number of road side unit. The base station will be act as a cloud server which gets the information from the road side unit and broadcast the message to the authorized user it will be a vehicle. The information from RSU also updated to the base station for every $10 \mathrm{~ms}$. This technology also communicate betweentwo vehicles also.

\section{RESULT AND IMPLEMENTATION}

Here we used the simulation to evaluate and show the result of our project. We adjusted the routing values carefully to evaluate the result efficiently. Let we shown off the results includes node deployment, throughput, routing overhead, packet delivery ratio. This Beacon Power Control Protocol

Shows the higher efficiency than the Maximum broadcast and efficiency routing(MBER).

By comparing this two algorithms the BPC can neglect the delay which occurs in the MBER algorithm. The delay is the main drawback to use this system. So we overcome the drawbacks and shown the result here is:

\section{A. Node deployment}

The nodes will be placed by giving the coordinates in order to its respect place.

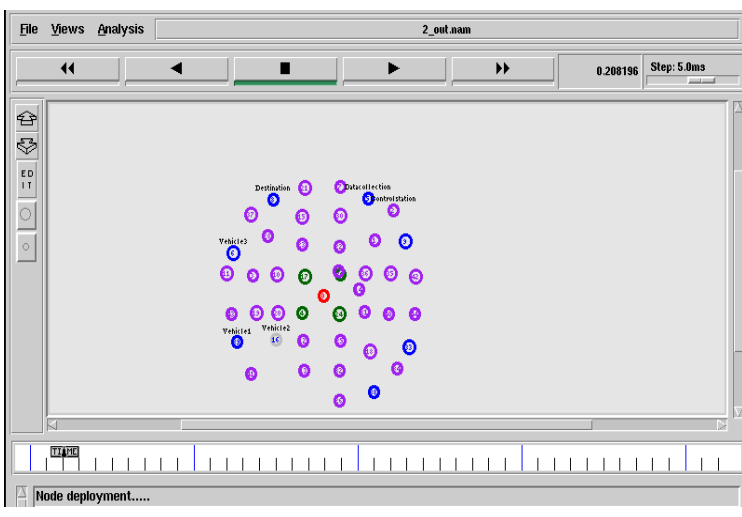

Fig. 4. Node deployment

\section{B. Throughput}

Yield is the quantity of effectively acknowledged bundles in a unit time and it is being spoken to in bps. Yield is determined initiating the content that forms the follow record and creates the output.

That is such evidence that even the hazardous level is increased, the delivery ratio of our proposed method will maintained(does not increase in interval). Hence it will not affect data transmission through the network. If the hazardous level is increased the throughput of proposed system is maintained.

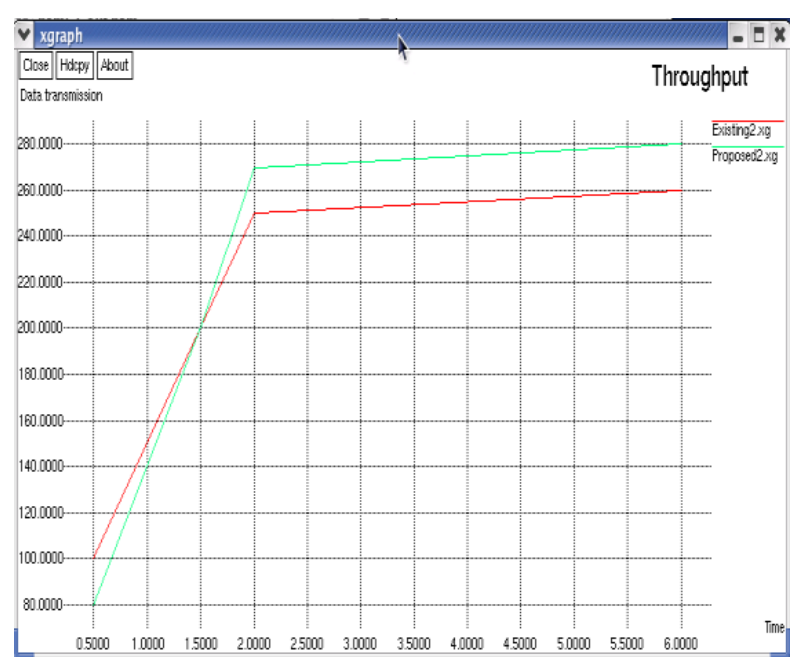

Fig. 5. Throughput

\section{Routing overhead}

Routing Overhead is the number of routing packets needed for network communication. Routing Overhead is calculated by using awk script which operates the trace file and produces the result.

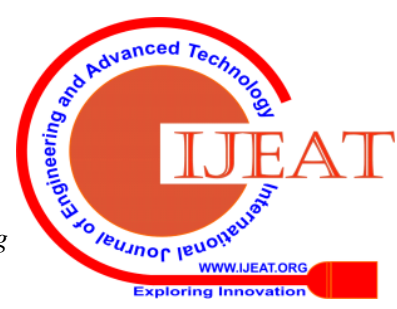




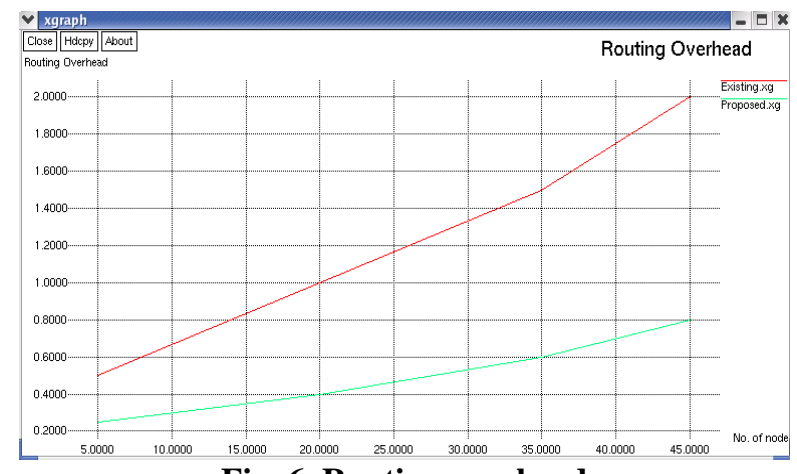

Fig. 6. Routing overhead

\section{Packet delivery ratio}

The count of Packet Delivery Ratio (PDR) tells the relay on the system. When all is said in done, PDR is being characterized as the proportion between the got parcels by the target and the created bundles by the source.

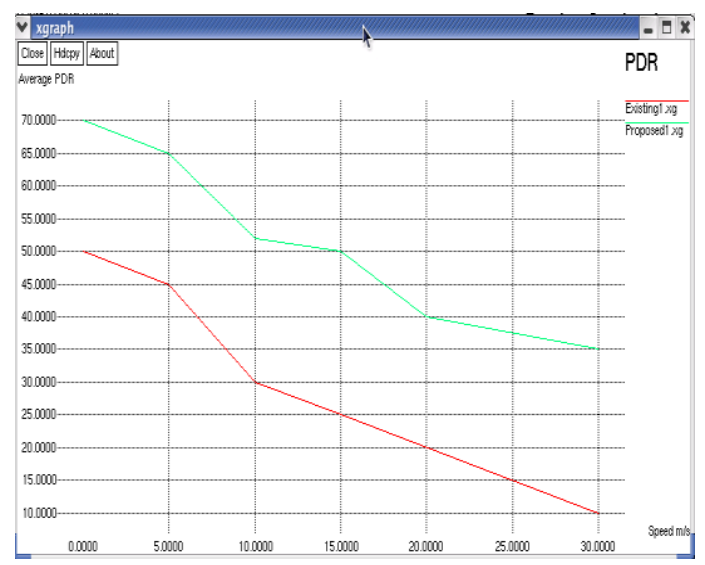

Fig.7 .Packet delivery ratio

\section{CONCLUSION}

VANET is an engaging remote correspondence development for updating avenue prosperity and information organizations.Security message giving condemning and critical information to every vehicle all over the place that must be sent continually to make all the vehicles careful about the status of their neighbors,yet sending this message causes orchestrate overhead and channel watch that must be lessened and cleared out.It is a promising gadget for watching the physical world with remote ensor that can distinguish process and pass on.

\section{REFERENCES}

1. K. G. Paterson, "Certificateless public key cryptography," in Asiacrypt, vol. 2894. Springer, 2003, pp. 452-473.

2. L. Atzori, A. Iera, and G. Morabito, "The internet of things: A survey," Computer networks, vol. 54, no. 15, pp. 2787-2805, 2010.

3. D. Boneh and X. Boyen, "Short signatures without random oracles," in International Conference on the Theory and Applications of Cryptographic Techniques. Springer, 2004, pp. 56-73.

4. D. Boneh, G. Di Crescenzo, R. Ostrovsky, and G. Persiano, "Public key encryption with keyword search,"

5. J. Daemen and V. Rijmen, The design of Rijndael: AES-the advanced encryption standard. Springer Science \& Business Media, 2013.

6. K. Huang, R. Tso, Y.-C. Chen, S. M. M. Rahman, A. Almogren.

\section{AUTHORS PROFILE}

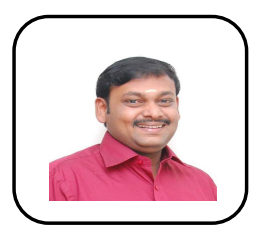

Mr.P.Karthikeyan, Associate professor, working in sri manakula vinayagar engineering college for the past 12 years. He done post graduate degree in Anna University. His research area is wireless sensor network. His specialized area is database and cloud. ISFE member, published many paper in wsn.

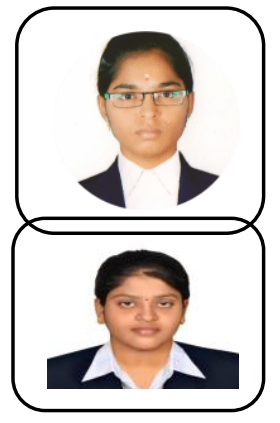

K.Sivaranjini, Studying B.Tech (computer science and engineering) in sri manakula vinayagar engineering college. Her area of interest in wireless sensor networks. Her specialized area is networking and database. networks. Her specialized area is cloud computing and Linux.

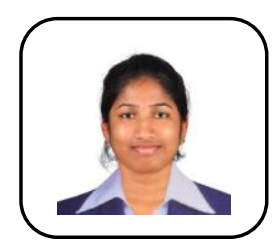

V.Priyadharshini, Studying B.Tech (computer science and engineering) in sri manakula vinayagar engineering college. Her area of interest in wireless sensor networks. Her specialized area is database and simulators.

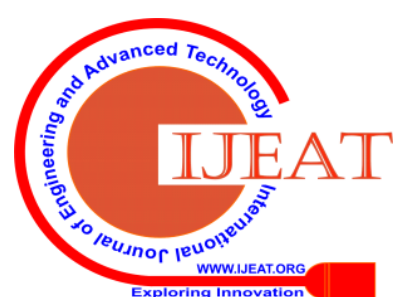

